\title{
Abordagens dos Fenômenos religiosos: cenários e desafios atuais
}

\author{
Approaches to religious Phenomena: current
}

scenarios and challenges

Abimar Oliveira de Moraes (iDa

\section{Resumo}

O presente artigo visa apresentar um suscinto relatório sobre a contribuição que a Associação Nacional de Pós-graduação e Pesquisa em Teologia e Ciências da Religião (ANPTECRE) vem dando ao processo de construção das novas abordagens dos fenômenos religiosos, dentro do debate acerca da identidade do Ensino Religioso no Brasil. Após consideração acerca do cenário de transformação no qual nos encontramos, o estudo dedica sua atenção à contribuição dada pela ANPTECRE para a aprovação da Diretrizes Curriculares Nacionais. Por fim, ilustra a contribuição que a Pós-graduação em Ciências da Religião e Teologia vem dando para a consolidação das relações entre Ensino Religioso, Ciências da Religião e Teologia, no cenário nacional, através da articulação promovida pela Associação e seu específico Grupo de Pesquisa sobre o tema.

Palavras-chave: Ensino Religioso. ANPTECRE. Área 44 da Capes. FONAPER.

\section{Abstract}

This article aims to present a brief report on the contribution that the National Association of Graduate Studies and Research in Theology and Religious Sciences (ANPTECRE) has been giving to the process of building new approaches to religious

\footnotetext{
a Pontifícia Universidade Católica do Rio de Janeiro (PUC-Rio), Rio de Janeiro, RJ, Brasil. Doutor em Teologia, e-mail: abimar@puc-rio.br/presidente@anptecre.org.br
} 
phenomena, within the debate about the identity of the Religious Education in Brazil. After considering the transformation scenario in which we find ourselves, the study devotes its attention to the contribution made by ANPTECRE for the approval of the National Curriculum Guidelines. Finally, it illustrates the contribution that the PostGraduation in Sciences of Religion and Theology has been giving, for the consolidation of the relations between Religious Education, Sciences of Religion and Theology, in the national scenario, through the articulation promoted by the Association and its specific Group Research on the topic.

Keywords: Religious education. ANPTECRE. Area 44 of Capes. FONAPER.

\section{Introdução}

Gostaria de abrir estas páginas de reflexão afirmando que terei como horizonte desta a conceituação de Ensino Religioso proposta por Aragão e Souza:

O Ensino Religioso é compreendido como educação sobre a religiosidade humana, devendo tratar pedagogicamente do conhecimento espiritual que existe entre e para além de todas as tradições místicas, religiosas e não religiosas, tematizando seus conteúdos simbólicos nos espaços e tempos sagrados, bem como os valores - e antivalores - que as espiritualidades, na prática, desenvolvem através da história. Trata-se, então, de comparar criticamente e interpretar os fatos - também religiosos - nos seus contextos históricos, em busca de significados mais profundos para esse patrimônio cultural da humanidade que são as espiritualidades filosóficas e religiosas (ARAGÃO; SOUZA, 2018, p. 43).

“Abordagens dos Fenômenos Religiosos: cenários e desafios atuais", ao refletir sobre esta questão ${ }^{1}$, a primeira coisa que me vem à mente é o cenário

\footnotetext{
${ }^{1}$ O presente artigo é fruto de minha participação, como presidente do Conselho Diretor da ANPTECRE, no X Congresso Nacional de Ensino Religioso, realizado na PUCPR. A convite do Fonaper, nossa Associação se reuniu com a coordenação da Área Ciências da Religião e Teologia e com a Soter, numa mesa de abertura do evento científico, no dia 18 de novembro de 2019. Gostaria, portanto, que o presente artigo fosse entendido muito mais como uma reflexão do presidente do Conselho Diretor vigente - nas atribuições do cargo que lhe foi confiado pelos associados - do que propriamente o posicionamento formal da ANPTECRE na matéria, embora o mesmo posicionamento esteja apresentado em algumas partes da reflexão.
} 
(talvez mais do que cenários) no qual a reflexão e a prática do Ensino Religioso, das Ciências da Religião e das Teologias se encontram na atualidade. Pareceme que o cenário é de uma época que se encerra.

A civilização ocidental e, nesta, a cristandade não tem mais papel hegemônico: múltiplas tradições culturais e religiosas vem se apresentando, reivindicando espaço e atenção. Gradualmente vão obtendo espaço e suas reivindicações vão sendo contempladas. Encontramo-nos num mundo que se tornou uma "aldeia global" e tudo isto incide, também, na percepção da religião e do seu significado.

\section{Alguns elementos de um cenário em transformação}

Na segunda metade do século passado, Heiler afirmava que "o mais seguro sustento, a suprema dignidade, a maior riqueza, a mais perfeita serenidade de um homem se encontram na religião, isto é, na relação com a realidade última e mais profunda" (HEILER, 1985, p. 9). Tal afirmação, sem dúvida alguma discutível, encontra em alguns setores da cultura atual dificuldade de se propor, uma vez que a religião é muitas vezes vinculada à ideologia, vista com suspeita e acusada de alienar e iludir. Ao mesmo tempo, ela continua sendo entendida, em outros setores, como realidade que acompanha o caminho da humanidade e a sustenta naquele confronto jamais resolvido com o mistério que envolve o próprio destino humano e do cosmo.

Assim, o que notamos é que a religião sofre os impactos das mudanças que acontecem no tecido social e cultural. De fato, em poucos anos o "antigo sistema", que enquadrava a experiência religiosa no Brasil como de hegemonia cristã-católica, vem se enfraquecendo:

Uma análise dos dados dos Censos Demográficos nos últimos 30 anos mostra uma tendência progressiva à diversificação religiosa no Brasil, uma vez que a Igreja Católica, que até 1980 era detentora de $89 \%$ do número de fiéis, vem perdendo adeptos, gradativamente, passando a congregar $65 \%$ de seguidores, em 2010. Ao longo desse período, observa-se, então, que a Igreja Católica perdeu 24 pontos percentuais no seu número de fiéis. Inversamente, o contingente de evangélicos de todas as confissões, quer os de missão, quer os pentecostais, 
passou de 6,6\% em 1980 para 22,1\% em 2010, registrando um aumento de 15,5 pontos percentuais (JACOB; HEES; WANIEZ, 2013, p. 10).

Outro aspecto importante de mencionar é que a religião vem perdendo sua indiscutível credibilidade. Há um decréscimo de sua plausibilidade. Assim, "o número de pessoas que se declaram sem religião também vem apresentando crescimento, ao passar de 1,6\% em 1980 para 8\% no último Censo, o que significa um aumento de 6,4 pontos percentuais" (JACOB; HEES; WANIEZ, 2013, p. 10).

A experiência religiosa se fez múltipla, diferenciada. Em muitos contextos, ela se impõe com força no tecido social e político, assumindo um papel de protagonismo evidente, algumas vezes, inclusive, em tom violento e desesperado, fazendo com que sua ressonância na experiência pessoal e coletiva seja marcada por ambiguidades. Fácil documentar atualmente, em especial nas redes sociais, a instrumentalização da religião tanto em seus aspectos interpessoais, como comunitários.

Em virtude de sua constitutiva exigência de "totalidade" e de "radicalidade", a religião pode ser afetada por muitos abusos. Tudo isto exige que reconheçamos a sua ambivalência e uma pluralidade de emergências que podem produzir variados tipos de interpretação nas múltiplas situações históricas e existenciais nas quais a experiência religiosa se apresenta no cenário nacional.

Outra ambivalência deriva da referência que uma determinada tradição religiosa queira privilegiar. Em linhas gerais, há uma tendência, nas mais distintas tradições religiosas, a remeter-se às origens, garantindo, assim, sua estabilidade e segurança em relação a um passado a qual somente aquela determinada tradição religiosa tem acesso e ao qual é fiel. A vinculação com as origens, pretendida dessa maneira exclusiva e excludente, pode tornar-se motivação para a conservação e a resistência ao processo irrenunciável da história.

Tal ambivalência é descrita por Bergson, em sua distinção entre as duas matrizes da religião: a estática e a dinâmica (BERGSON, 1978, p. 85-219). Precisamente, é na análise da experiência mística que faz uso do recurso inovativo presente na dimensão dinâmica que Bergson identifica a 
contribuição mais alta da religião no processo de amadurecimento pessoal e coletivo (BERGSON, 1978, p. 178-197).

No contexto atual, assistimos a um retorno à acentuação das distinções entre sagrado e profano, entre espiritual e mundano. Tomando como referência a tradição cristã, sabemos que tais distinções trazem consigo a construção de dualismos de matriz teológica (GARCÍA RUBIO, 1989, p. 267-278) que separam o âmbito histórico do existencial.

Assim sendo, a religião não pode se presumir num espaço "separado". Ele não se encontra no espiritual, em detrimento do mundano e, nem viceversa. Não é possível, portanto, apelar a "recursos estranhos" à história para compreendê-la e praticá-la. Quando o fazemos corremos o grave risco de emarginá-la, de distanciá-la da percepção atual que a humanidade tem de si mesmo e da sua história.

Isto exige que nos preocupemos com a função ou papel que a religião assume no processo existencial e histórico de uma pessoa e/ou coletivo. Este aspecto, hoje, tornou-se muito mais importante do que a concepção acerca da transcendência entendida como dado interior e constitutivo da vida humana.

Outro elemento deste cenário que estamos descrevendo que gostaríamos de abordar é aquele das novas formas de religiosidade, isto é, as expressões e modalidades religiosas que se colocam ao lado e, em algumas situações, se contrapõe às tradições religiosas consolidadas. De fato, estamos imersos num movimento de proliferação religiosa de várias matrizes.

De um lado, assistimos ao surgimento de movimentos internos às tradições religiosas consolidadas. Estes, em linhas gerais, não tendem a contrapor-se a elas, mas buscam a "purificação" ou transparência da mensagem e das estruturas de agregação e de formação da identidade e missão do grupo religioso. Do outro lado, notamos, com sempre maior frequência, o surgimento de movimentos que tendem a se apresentar como alternativa às religiões localmente mais difusas.

Na origem dessas novas formas, podemos identificar o fenômeno da secularização, caracterizado por vários elementos que resultam, paradoxalmente, negativos e positivos: progresso científico; conquista da liberdade; deslocamento do dado religioso à esfera privada e pessoal; esvaziamento das relações interpessoais; desumanização; desejo de 
fraternidade/sororidade e de acolhida; vontade de domínio das energias não cientificamente controláveis; presunção de posse de determinados dons de conhecimento e de domínio da realidade; são alguns deles.

Diante de tais movimentos religiosos, cujas propostas, muitas vezes são construídas sobre o "vazio" deixado pelas tradições religiosas consolidadas, há o risco de assumir uma atitude de defesa negativa da própria tradição religiosa e de um exasperado contra-proselitismo. Parece-me necessária uma ação positiva, de escuta mútua e de busca paciente e sincera das respostas aos interrogativos, que ambas as realidades se põem uma a outra.

Assim, vemos como, num espaço muito curto de tempo, passamos da denúncia do eclipsar do sagrado a um proliferar religioso incontrolável. Consequência disto tudo: a necessidade de a educação debruçar-se sobre a religião.

\section{Rumo às Diretrizes Curriculares Nacionais}

Como teólogo pastoral cristão, analiso o interessante fenômeno da proclamação de "novas etapas evangelizadoras" por parte de diversas tradições cristãs históricas². A necessidade de pensar e propor uma "nova etapa" diz claramente que a relação das tradições consolidadas com o espaço público está fragilizada ou não existe mais. A necessidade da proposição de uma "nova evangelização" traz juntamente consigo a pergunta acerca da nova educação religiosa que precisa ser proposta e consolidada.

Na busca pela construção duma nova abordagem entre religião e educação, no Brasil, vem ganhando força a análise do fenômeno religioso. Ulrich e Gonçalves afirmam:

É necessário, portanto, deixar claro que o objeto de estudo do Ensino Religioso não é o Transcendente, nem o estudo das religiões, tampouco o ensino dos

\footnotetext{
2 Talvez uma das mais significativas tentativas, nestes últimos anos, seja aquela empreendida pela igreja católica romana, ao celebrar o Concílio Vaticano II. Um Concílio eminente pastoral e, portanto, que objetiva a transformação da relação entre essa tradição religiosa consolidada e o espaço social no qual ela se encontra. Trata-se de uma tentativa toda ainda em curso e, portanto, não isenta de tensões e falências, mas que no meu juízo se faz necessária, não tanto para a sobrevivência da tradição religiosa, mas bem sim, pela contribuição que a mesma pode aportar à sociedade como um todo.
} 
valores ético-morais. O novo foco do Ensino Religioso é o estudo do fenômeno religioso, articulando-se a partir da escola, que é um espaço multicultural e multirreligioso (ULRICH; GONÇALVES, 2018, p. 22).

A atenção à experiência religiosa aparece fortemente justificada, trazendo consigo o esforço de construir uma proposta a partir de bases cada vez mais antropológicas e, sempre menos vinculadas a uma determinada confissão religiosa.

Tal proposta, porém, parece-me ainda encontrar resistências tanto por parte dos que sustentam a "primazia do confessional" sobre o "fenômeno religioso"; bem como daqueles que suspeitam que o fenômeno religioso possa fazer parte de um processo educativo confessional, tutelado pelo Estado, que é laico.

Numa sociedade democrática, a escola pública deveria ser a agência educativa da qual a sociedade plural se serve como lugar de elaboração crítica e sistemática da cultura compreendida a cultura religiosa - em vista da formação humana e civil da personalidade através daquele canal, não único, mas privilegiado, que é a instrução.

Em coerência com este conceito de escola a ser perseguido, entendido, neste contexto plural, laico e democrático, em sua específica vocação e, portanto, também, em suas limitações objetivas, entendo que o Ensino Religioso não pode fundamentar-se sobre uma legitimação pastoral, isto é, como momento da atividade catequética das tradições religiosas; nem sobre pressupostos de tipo ideológico; e nem de tipo diplomático, onde a religião apresentada é aquela de Estado.

O que percebo é que nos encontramos num processo de busca da legitimação pedagógica do Ensino Religioso (ARAGÃO; SOUZA, 2018, p. 51-55). Tal busca está calcada sobre uma série de argumentos. Em algumas propostas, estes argumentos - ou, ao menos, alguns deles - estão integrados. Em outras, estão separados.

O primeiro deles diz respeito à análise, do ponto de vista antropológico, de se/como é comum ao humano o interrogar-se sobre o sentido fundamental da vida e se a religião busca dar respostas coerentes a tal interrogação. 0 Ensino Religioso ajudaria o educando a crescer habilitando-o a pôr-se 
corretamente a questão religiosa e a confrontar-se criticamente com as respostas provenientes da religião e de outros sistemas de significado.

O segundo diz respeito à análise, de se/como, do ponto de vista histórico-cultural, a religião, no Brasil, é um dado de fato na história passada e presente, podendo ser identificada como parte integrante, uma das "raízes" do patrimônio cultural brasileiro. O Ensino Religioso deve tornar possível tal abordagem histórica, crítica e sistemática.

O terceiro deles diz respeito, do ponto de vista educativo, se o Ensino Religioso, dentro do projeto político pedagógico escolar, contribui para formar a pessoa humana na integralidade de suas dimensões e, em particular, visa educar a capacidade de juízo crítico e de decisões responsáveis. Nesse contexto, o Ensino Religioso buscará apontar o papel que a religião desempenha no promover historicamente os direitos humanos, oferecendo competência ético-religiosa que contribui no aperfeiçoamento da capacidade de juízo e opções que permite a construção crítica da sociedade, desmascarando falsos absolutos e opondo-se a qualquer uso instrumental da pessoa e da natureza.

O quarto diz respeito, do ponto de vista jurídico-legislativo, se/como o Estado laico reconhece e garante o direito à cultura de todos os cidadãos sem discriminação. Neste contexto, a cultura (ou culturas) religiosa deve ser reconhecida objetivamente, por conteúdos de sabedoria e por valores éticos transmitidos, como parte irrenunciável e qualificante da cultura humana. 0 Estado deve regular juridicamente o Ensino Religioso na escola pública e, consequentemente, dispor para que o mesmo tenha condições paritárias àquelas reservadas às outras disciplinas.

É inegável que avançamos nesta dimensão da legitimação escolar do Ensino Religioso. Contudo, dentro deste contexto, permanece aberto o debate sobre o papel de corresponsabilidade das tradições religiosas, uma vez que, em algumas legislações estaduais, elas estão envolvidas diretamente com o Estado na gestão das atividades didáticas (JUNQUEIRA; HOLANDA; CORRÊA, 2015, p. 32-33).

O mesmo debate permanece vivo quando nos debruçamos sobre a exigência ou não da confessionalidade dos conteúdos do ensino religioso, 
como no caso do decreto número 7.107, de 11 de fevereiro de 2010, que promulga o Acordo entre o Governo da República Federativa do Brasil e a Santa Sé relativo ao estatuto jurídico da igreja católica no Brasil, firmado na Cidade do Vaticano, em 13 de novembro de 2008. Neste acordo, no artigo 11, lê-se:

A República Federativa do Brasil, em observância ao direito de liberdade religiosa, da diversidade cultural e da pluralidade confessional do País, respeita a importância do ensino religioso em vista da formação integral da pessoa. $\$ 1^{\circ}$. O ensino religioso, católico e de outras confissões religiosas, de matrícula facultativa, constitui disciplina dos horários normais das escolas públicas de ensino fundamental, assegurado o respeito à diversidade cultural religiosa do Brasil, em conformidade com a Constituição e as outras leis vigentes, sem qualquer forma de discriminação (BRASIL, 2010).

Imediatamente após a promulgação do Acordo, no mesmo ano de 2010, a Procuradoria-Geral da República, sustentando 0 parecer de inconstitucionalidade do decreto 7.107, solicita o posicionamento do Supremo Tribunal Federal. Em 27 de setembro de 2017, o Supremo vota pela improcedência, entendendo que o Ensino Religioso confessional nas escolas públicas não fere a Constituição Federal, por não poder ser identificado com o proselitismo (BRASIL, 2017, “a” e “b”).

Sem entrar em outras questões pertinentes, gostaria de observar que as condições do crescente pluralismo religioso no cenário social brasileiro obrigam todos os projetos de Ensino Religioso ${ }^{3}$, não somente a abrir-se a objetivos educativos de tolerância e de diálogo, mas ao confronto construtivo das tradições religiosas entre si, com outras visões da vida e com sistemas de significado não religiosos.

Penso que a aprovação e instituição das Diretrizes Curriculares Nacionais para o curso de licenciatura em Ciências da Religião, no apagar das luzes de 2018 (28 de dezembro), vitória conjunta do FONAPER, da SOTER e da ANPTECRE, possa nos ajudar a enfrentar tais debates e resistências (BRASIL, 2018).

\footnotetext{
${ }^{3}$ Em artigo de 2018, Andrade e Ferreira, ao falarem dos dilemas epistemológicos do Ensino Religioso, apresentam três macromodelos: o interconfessional; o confessional; e o histórico (ANDRADE; FERREIRA, 2018, 61-64).
} 
Nossa Associação sempre ressaltou a fundamental importância do desenvolvimento das Diretrizes para o conjunto da recém-criada Área de Ciências da Religião e Teologia, pela Capes ${ }^{4}$. A aprovação das Diretrizes Curriculares dos cursos de graduação em Teologia (BRASIL, 2016) e das licenciaturas em Ciências da Religião foram importantes conquistas para a nossa Área.

A ANPTECRE tem o entendimento de que, para o conjunto de nossa Área, é importante que os cursos de Teologia e de Ciências da Religião estejam regulamentados e tenham diretrizes claras, já que nossos associados necessitam do fortalecimento de suas graduações.

Por essa razão, a época, sugerimos, não obstante às diversas nomenclaturas empregadas pelos cursos de graduação e pós-graduação, que as Diretrizes adotassem a designação “Ciências da Religião”, em conformidade com a nomenclatura adotada pela Capes, por nossa Árvore do Conhecimento e por nossa Associação que aglutina todos os Programas avaliados pelo Sistema Nacional de Pós-Graduação5.

Tal como aconteceu com as Diretrizes de Teologia, a Árvore de Conhecimento da Área Ciências da Religião e Teologia apresentou-se como parâmetro seguro para a elaboração das Diretrizes Curriculares de Ciências da Religião, tomando como base, o entendimento de que as Ciências da Religião constituem campo de estudo específico e referência para o estudo e compreensão do fenômeno religioso e suas manifestações. Dessa forma, a Associação propôs que as Diretrizes Curriculares, aprovadas em 2018, estivessem profundamente sintonizadas com a episteme da Área.

\footnotetext{
${ }^{4}$ Em 2016, a Área Ciências da Religião e Teologia foi criada pela Portaria 16, publicada no Diário Oficial da União de 13 de outubro do mesmo ano. Inicialmente, a Capes denominou, em 2016, a Área 44 de Teologia. Após solicitação formal dos vinte um (21) Programas que a compunham, naquele momento, a designação passou a ser Ciências da Religião e Teologia, a partir da resolução $n^{\circ}$ 1/2017.

${ }^{5}$ A ANPTECRE participou da Audiência Pública sobre as Diretrizes Curriculares dos cursos de licenciatura em Ciências da Religião, mediante a presença do Presidente do Conselho Científico, Prof. Dr. Rodrigo Coppe Caldeira, ocorrida em Brasília, no dia 18 de setembro de 2018. Sobre a participação da ANPTECRE na referida Audiência ver o relatório do Conselho Científico registrado na Ata da Assembleia Ordinária da ANPTECRE, realizada no Rio de Janeiro, na PUC-Rio, no dia 17 de setembro de 2019.
} 
Nas Diretrizes, a religião foi entendida como esfera constituinte da realidade social; como realidade que está presente na vida dos/as educando/as. Devido essa presença e complexidade, é fundamental que esse tema seja abordado na escola e que seja feito por docentes com formação específica, com conhecimentos teórico-metodológicos, com atenção às diversas tradições religiosas, com formação pedagógica consistente.

Destaque-se a importância que o texto das Diretrizes confere ao estudo da religião de modo não confessional, tendo em vista finalidades sociais, quais sejam: formação humana-integral, cidadania e atitude dialógica, à luz das diversidades religiosas, étnicas, culturais e de gênero que se manifestam no cenário nacional.

De fato, as Diretrizes entendem que a formação específica em Ensino Religioso estará assegurada mediante:

1. Apropriação dos fundamentos históricos, epistemológicos e metodológicos do Ensino Religioso de natureza não confessional e não proselitista, necessários à sua docência em diferentes etapas e modalidades da Educação Básica; 2. Análise, criação e uso de materiais didáticos, textos, tecnologias digitais e metodologias significativas de aprendizagens para o Ensino Religioso (BRASIL, 2018).

Outro destaque é que nelas o mundo religioso sentido pelo(a) educando(a) é ponto de partida do processo ensino-aprendizagem. Isto pode ser depreendido das sete competências a serem desenvolvidas ao longo do curso de licenciatura:

I - Apropriar-se dos elementos constituintes das diferentes tradições/movimentos religiosos e filosofias de vida, a partir de pressupostos científicos, estéticos e éticos, para entender e explicar a realidade e colaborar para a construção de uma sociedade justa, democrática e inclusiva; II - Conhecer as manifestações religiosas e filosofias de vida em diferentes tempos, espaços e territórios, a fim de promover a valorização e o respeito à diversidade de saberes e experiências socioculturais peculiares às religiões; III - Analisar as relações entre as tradições/movimentos religiosos e os campos da cultura, arte, política, economia, saúde, sexualidade, ciência, tecnologias, mídias e meio ambiente para construir leituras críticas de mundo no contexto do exercício da cidadania; IV Exercer a docência do Ensino Religioso em todas as etapas e modalidades da Educação Básica, em espaços formais e não formais, por meio de práticas pedagógicas fundamentadas na interculturalidade e na ética da alteridade, com vistas a promover o respeito ao outro e aos direitos humanos; $\mathrm{V}$ - Reconhecer a diversidade de crenças, pensamentos, convicções, modos de ser e viver, para 
valorizar a diversidade de indivíduos e grupos sociais, seus saberes, identidades, culturas e potencialidades; VI - Posicionar-se frente aos discursos e práticas de intolerância, discriminação e violência de cunho religioso, de modo a assegurar os direitos humanos no constante exercício da cidadania e da cultura de paz; VII - Investigar e propor a resolução de situações-problema com base nos conhecimentos específicos de sua formação (BRASIL, 2018).

\section{A contribuição da ANPTECRE}

As profundas mudanças culturais que se desenvolvem rapidamente põem em foco algumas urgências. A primeira diz respeito à consideração da dignidade e da responsabilidade dos indivíduos que devem ser afirmadas e reconhecidas em todos os níveis de sua existência. A atenção à dignidade e à responsabilidade do indivíduo traz consigo uma nova modalidade de relação complexa e ramificada, não controlável, onde as relações e as comunicações são imprevisíveis e as instituições educativas vem perdendo a capacidade de governar e, muitas vezes, têm dificuldade de construir uma linguagem comum capaz de instaurar solidariedade profunda, partilha e corresponsabilidade.

Neste cenário, parece-me de grande importância o surgimento, crescimento e consolidação, nos últimos cinquenta anos, dos centros acadêmicos de pós-graduação e pesquisa em Ciências da Religião e Teologia em nosso país. Através deles, as análises sobre os fenômenos religiosos e suas abordagens mais convenientes, nesse contexto cultural, vão se multiplicando. Muitas pesquisas vêm evidenciando o impacto que os fenômenos religiosos têm sobre a existência individual e coletiva. A própria tradição doutrinal e educativa de grupos religiosos está sendo colocada na importante tarefa de ser repensada e distinguida do projeto pastoral educativo (no caso das escolas confessionais).

Qual a relevância que uma determinada tradição religiosa tem sobre a pessoa? Qual horizonte de sentido ela é capaz de abrir ao indivíduo? Em que medida essa tradição religiosa consente explorar as aspirações individuais? São algumas das questões fundamentais que o novo contexto cultural vem colocando às tradições religiosas.

Os estudos que visam enfrentar essas questões vêm auxiliando as tradições religiosas no Brasil a redimensionar e autoavaliar suas contribuições 
específicas e singulares no campo religioso nacional. A articulação das diversas pesquisas, tanto no campo das Teologias, como no das Ciências da Religião, colocam à disposição da prática do Ensino Religioso uma bagagem incalculável, desde que venham oportunamente valorizadas, permitindo uma importante diferenciação entre ensino religioso e pastoral escolar, por exemplo (MORAES; SANTOS, 2021; SANTOS, 2020).

Nesse sentido, não é por acaso que o primeiro Grupo de Trabalho aprovado pela ANPTECRE seja o de "Religião e Educação". Este Grupo de Trabalho, atualmente coordenado pela Profa. Elisa Rodrigues (UFJF), pelo Prof. Sérgio Rogério Azevedo Junqueira (UEPA), pela Profa. Andréa Silveira de Souza (UFJF), pelo Prof. Lusival Antônio Barcellos (UFPB) e pela Profa. Laude Brandenburg (EST), vem organizando estudos e pesquisas sobre a relação entre educação, cultura e religião, um campo que se abre sistematicamente aos pesquisadores de Ciências da Religião e Teologia e, em especial, de Ciências da Religião Aplicada e Teologia Prática. No VII Congresso Nacional da ANPTECRE, o Grupo de Trabalho assim se apresentou:

Com perspectiva interdisciplinar, a intenção deste GT é compreender os diferentes processos de ensino e aprendizagem em espaços de formação e de ensino. Esse núcleo abrange temas como religião como objeto de estudo, ensino religioso, ensino sobre religião em ambientes escolares, religião nos currículos escolares, educação e religião na esfera pública, diversidades religiosas e étnicoculturais, formação inicial e continuada para o ensino sobre religião, metodologias e subsídios pedagógicos para o ensino sobre religião. Tais eixos visam o debate e o desenvolvimento do conhecimento sobre o tema religião e educação, bem como a socialização dos resultados e da produção desse campo para a educação brasileira. Objetiva-se com essa discussão a compreensão, a transformação e a consolidação de práticas e políticas educacionais relacionadas ao fenômeno religioso, aqui, apresentadas como plataformas para a formação de cidadãos e cidadãs cientes de seus direitos e deveres (GRUPO DE TRABALHO RELIGIÃO E EDUCAÇÃO, 2019).

É precisamente este horizonte aberto pela pesquisa acerca dos fenômenos religiosos, em especial desenvolvidos em nossos Programas de Pós-Graduação em Ciências da Religião e Teologia, que pode nos ajudar a elaborar um projeto unitário, rigorosamente fundado e coerente, no qual o Ensino Religioso se repensa, tendo presente, sobretudo, a pessoa, sua identidade e seu projeto de orientação de vida, e confirma que o estudo dos 
fenômenos religiosos é decisivo na tentativa de compreensão da mudança de época na qual nos encontramos.

Isto porque a época atual tem um forte acento "hermenêutico". Creio que estamos imersos numa cultura orientada a decifrar a experiência humana e a encontrar um significado para ela. Neste contexto cultural, o Ensino Religioso apresenta-se atento às experiências humanas concretas, buscando evidenciar a dimensão religiosa de tais experiências e aprofunda suas raízes na exigência de solidariedade com a vida (nas suas mais variadas expressões).

O Ensino Religioso se situa, assim, coerentemente num contexto que exige uma pesquisa interdisciplinar, complexa e articulada. Nessa pesquisa, Ciências da Religião e Teologia, embora com epistemologias e abordagens diversas, são importantes. Nenhuma das duas pode entender-se como única e exclusiva, pois ambas debruçam-se sobre o sujeito humano e sua situação concreta, em busca de uma apresentação do conceito "religião" como recurso de promoção humana e histórico-social.

O Ensino Religioso tem capital importância no processo de apresentação do conceito "religião", em que religião é fonte de culturas, não se identificando, porém, de maneira exclusiva com nenhuma delas, mas sendo capaz de fermentar todas elas. Onde a tarefa da religião seja aquela de integrar os diversos grupos culturais, na construção de uma sociedade mais vivível, mais pacífica, mais sustentável, mais justa, mais fraterna.

É isto que as pesquisas e os Programas de Pós-Graduação associados à ANPTECRE vêm buscando fazer e propor dentro do Sistema Nacional de PósGraduação no Brasil. Sabemos ser um caminho árduo, mas necessário de ser feito. Alegramo-nos por contar com a companhia do FONAPER, da SOTER e da Coordenação da Área 44 nessa estrada a ser construída, enquanto por ela caminhamos. É uma bela aventura que sabemos iniciada, mas não concluída.

\section{Considerações finais}

O presente artigo buscou evidenciar, brevemente, o papel da ANPTECRE diante do cenário e desafios atuais que se apresentam ao Ensino Religioso. É sabido que a natureza da Associação é contribuir para a 
consolidação da pós-graduação e da pesquisa na Área. Ao participar das ações e do debate acerca da identidade do Ensino Religioso, a ANPTECRE compreende que não é possível que os Programas de Pós-graduação e, a partir deles seus pesquisadores e pesquisadoras, olhem para tal realidade e seus desafios sem apontar possíveis contribuições e soluções.

O Ensino Religioso é capaz de prover ao ser humano o caminho do conhecimento de si mesmo, dos outros e outras humanos, e do mundo. A tarefa de educar as novas gerações não é simplista e fácil. Não podemos contar apenas com a boa vontade. É preciso ardor científico por parte de todos os interlocutores.

Uma visão pessimista pode apenas enumerar os mais diferentes problemas que se descortinam no espaço escolar, porém as pesquisas em nossa Área podem apontar para o valor de cada ser humano e dos esforços necessários para dar a todos dignidade e esperança da beleza que existe e que, todos os dias, se descortina diante de todos nós.

Devemos refletir sobre uma proposta de Ensino Religioso que esteja preparada para as demandas das novas gerações, dedicando-se à reforma de suas práticas pedagógicas e atualização de seus conteúdos. É necessário pensar no valor e na grandeza dessa missão tão necessária para a formação de pessoas que saibam viver a fraternidade/sororidade como um serviço de amor e ideal de vida. Aqui a ANPTECRE pode e deve desempenhar um papel relevante juntamente com o FONAPER e outras associações científicas.

\section{Referências}

ANDRADE, P.; FERREIRA, I. V. Ensino Religioso e Capitais culturais. Estudos Teológicos, São Leopoldo, v. 58, n. 1, p. 57-72, jan./jun. 2018. Disponível em: http://periodicos.est.edu.br/index.php/estudos_teologicos/article/view/3174/pdf.

ARAGÃO, G.; SOUZA, M. Transdisciplinaridade, o campo das Ciências da Religião e sua aplicação ao Ensino Religioso. Estudos Teológicos, São Leopoldo, v. 58, n. 1, p. 42-56, jan./jun. $2018 . \quad$ Disponível em: http://periodicos.est.edu.br/index.php/estudos_teologicos/article/view/3261/pdf. Acesso em: 15 jan. 2021.

BERGSON, H. As duas fontes da Moral e da Religião. Rio de Janeiro: Zahar, 1978. 
BRASIL. Decreto $n^{\circ} 7.107$, de 11 de fevereiro de 2010. Promulga o Acordo entre 0 Governo da República Federativa do Brasil e a Santa Sé relativo ao Estatuto Jurídico da Igreja Católica no Brasil, firmado na Cidade do Vaticano, em 13 de novembro de 2008. Disponível em: http://www.planalto.gov.br/ccivil_03/_ato20072010/2010/decreto/d7107.htm. Acesso em: 15 jan. 2021.

BRASIL. Ministério da Educação. Conselho Nacional de Educação. Resolução $n^{\circ} 4$, de 16 de setembro de 2016. Institui as Diretrizes Curriculares Nacionais para o curso de graduação em Teologia e dá outras providências. Disponível em: http://portal.mec.gov.br/index.php?option=com_docman\&view=download\&alias=4 8421-rces004-16-pdf\&category_slug=setembro-2016-pdf\&ltemid=30192. Acesso em: 15 jan. 2021.

BRASIL. Ministério da Educação. Conselho Nacional de Educação. Resolução $n^{\circ} 5$, de 28 de dezembro de 2018. Institui as Diretrizes Curriculares Nacionais para o curso de licenciatura em Ciências da Religião e dá outras providências. Disponível em: http://portal.mec.gov.br/docman/janeiro-2019-pdf/105531-rcpo05-18/file. Acesso em: 15 jan. 2021.

BRASIL. Supremo Tribunal Federal. Ação direta de inconstitucionalidade $n^{\circ}$ 4439/DF Distrito Federal. Relator: Ministro Roberto Barroso. Petição inicial, 30 jul. 2010. Disponível em: http://redir.stf.jus.br/estfvisualizadorpub/jsp/consultarprocessoeletronico/Consultar ProcessoEletronico.jsf?seqobjetoincidente=3926392. Acesso em: 15 jan. 2021.

BRASIL. Supremo Tribunal Federal. Ação direta de inconstitucionalidade n 4439/DF Distrito Federal. Relator: Ministro Roberto Barroso. Certidão de Julgamento, 27 set. 2017. Disponível em: http://redir.stf.jus.br/estfvisualizadorpub/jsp/consultarprocessoeletronico/Consultar ProcessoEletronico.jsf?seqobjetoincidente=3926392. Acesso em: 15 jan. 2021.

GARCÍA RUBIO, A. Unidade na pluralidade. O ser humano à luz da fé e da reflexão cristãs. São Paulo: Paulinas, 1989.

GRUPO DE TRABALHO RELIGIÃO E EDUCAÇÃO. Ementa para o VII Congresso Nacional da ANPTECRE. Disponível em: http://eventospucrio.teo.br/files/Listagem\%20de\%20GT\%20e\%20ST\%2020Aprovados.pdf. Acesso em: 15 jan. 2021.

HEILER, F. Le religioni dell'umanità. Milano: Jaca Book, 1985.

JACOB, C. R.; HEES, D. R.; WANIEZ, P. Religião e Território no Brasil: 1991/2010. Rio de Janeiro: PUC-Rio, 2013.

JUNQUEIRA, S. R. A.; HOLANDA, A. M. R.; CORRÊA, R. L. T. Ensino Religioso: aspectos legais. In: JUNQUEIRA, S. R. A. (Org.). Ensino Religioso no Brasil. Florianópolis: Insular, 2015. 
MORAES, A. O.; SANTOS, B. F. La misión catequética de la escuela católica en Brasil: para un proyecto educativo pastoral a la luz del Directorio para la Catequesis. In: TEJO, J. D.; MORAES, A. O.; OSPINO, H. (Ed.). Catequesis para uma nueva normalidad. Pistas provocativas. Santiago: Ediciones Universidad Finis Terrae, 2021. Disponível em: http://www.pos.teo.puc-rio.br/wp-content/uploads/2021/05/Catequesis-para-

una-Nueva-Normalidad.pdf. Acesso em: 15 jan. 2021.

SANTOS, B. F. Por uma Escola em Pastoral: atuais desafios evangelizadores da escola católica na educação básica. 2020. 108p. Dissertação (Mestrado em Teologia) Programa de Pós-graduação em Teologia, Pontifícia Universidade Católica do Rio de Janeiro, Rio de Janeiro, 2020. Disponível em: https://www.maxwell.vrac.pucrio.br/48603/48603.PDF. Acesso em: 15 jan. 2021.

ULRICH, C. B.; GONÇALVES, J. M. O estranho caso do Ensino Religioso: contradições legais e questões epistemológicas. Estudos Teológicos, São Leopoldo, v. 58, n. 1, p. 1427, jan./jun. 2018. Disponível em: http://periodicos.est.edu.br/index.php/estudos_teologicos/article/view/3284/pdf. Acesso em: 15 jan. 2021. 